\title{
O uso de jogos digitais como ferramenta de auxílio para o ensino de Física
}

\section{The use of digital games as a tool to support the teaching of physics}

\author{
João Carlos Krause (krause@ @antoangelo.uri.br) \\ Universidade Regional Integrada do Alto Uruguai e das Missões, Campus de Santo Ângelo. \\ Denise Felber (denisefelber@gmail.com) \\ Fundação Educacional Machado de Assis (FEMA), Santa Rosa. \\ Luciana Dornelles Venquiaruto (venquiaruto@uri.com.br) \\ Universidade Regional Integrada do Alto Uruguai e das Missões, Campus de Erechim.
}

\section{Resumo:}

Este estudo teve como objetivo o desenvolvimento de um objeto de aprendizagem que utiliza a tecnologia da informação e comunicação aliada aos jogos digitais, mais especificamente RPG (Roleplaying Game), para o ensino de Física. A pesquisa possui uma abordagem qualitativa e quanto a sua finalidade foi caracterizada como aplicada. $\mathrm{O}$ objeto de aprendizagem, constituído de um jogo RPG em formato digital, foi desenvolvido para uso dos alunos do ensino médio, tendo como delimitação os conteúdos de mecânica. A aplicação do objeto como recurso pedagógico ocorreu com alunos da rede particular de ensino médio na cidade de Santa Rosa/RS. Por intermédio da aplicação de um questionário após a aplicação do jogo, foi possível verificar que os alunos gostaram do jogo, sendo que consideraram que o uso do RPG na aula fez com que ela fosse mais proveitosa e possibilitou uma melhor comunicação entre alunos e professor. Assim, pode-se concluir que o RPG permitiu ao professor interagir com o grupo de alunos percebendo as dificuldades de cada um e possibilitando a identificação de estratégias que auxiliem na resolução de problemas e na melhor absorção do conteúdo por parte do educando. Verificou-se também, que a grande maioria dos estudantes, mais de $84 \%$, gostaram do jogo e consideraram o uso do jogo um recurso que agrega diversão e interação em sala de aula, permitindo que os saberes trabalhados no Ensino da Física sejam expressos através de uma linguagem diferente que estimula e explora as potencialidades dos educandos.

Palavras-chave: Games; RPG; Ensino de Física.

\begin{abstract}
This study aimed to develop a learning object that uses information technology and communication allied to digital games, more specifically RPG (Roleplaying Game), for the teaching of Physics. The research has a qualitative approach and how its purpose has been characterized as applied. The learning object, made up of an RPG game in digital format, was developed for the use of the high school students, having as delimitation the contents of mechanics. The application of the object as a pedagogical resource occurred with students of the private high school network in the city of Santa Rosa / RS. Through
\end{abstract}


the application of a questionnaire after the application of the game, it was possible to verify that the students liked the game, and considered that the use of RPG in the classroom made it more useful and enabled better communication between students and teacher. Thus, it can be concluded that the RPG allowed the teacher to interact with the group of students perceiving the difficulties of each one and enabling the identification of strategies that help in solving problems and in the better absorption of content by the learner. It was also verified that the great majority of the students, more than $84 \%$, liked the game and considered the use of the game a resource that adds fun and interaction in the classroom, allowing the knowledge worked in the Teaching of Physics to be expressed through of a different language that stimulates and exploits the potentialities of learners.Keywords: Games, RPG, Physics Teaching.

Key Words: Games; RPG; Physics Teaching.

\section{INTRODUÇÃO}

$\mathrm{Na}$ sociedade como um todo acontecem grandes mudanças tecnológicas que influenciam em nosso modo de vida. Os aparelhos eletrônicos ganham cada vez mais espaço em nossas atividades diárias, com o objetivo de facilitar as tarefas, a comunicação e proporcionar diversão e entretenimento. Indústrias, meios de transporte e comunicação, prestação de serviço e atividades de ensino acompanham esse processo de informatização.

Conforme Lévy (1993) existem três importantes aspectos a serem considerados em relação a sociedade contemporânea: velocidade de surgimento e renovação dos saberes; quantidade de conhecimentos sempre crescente; e existência de tecnologias que amplificam, exteriorizam e modificam muitas funções cognitivas.

Da mesma forma que as inovações tecnológicas revolucionam a interação entre as pessoas é preciso adequar os métodos de aprendizagem para a nova geração de alunos que cresce em meio a essas mudanças. As instituições de ensino buscam o uso da tecnologia para oferecer aos alunos mídias interativas que possam enriquecer as aulas. Neste contexto, os jogos digitais surgem como um recurso didático que contém características que podem trazer uma série de benefícios para o ambiente escolar.

As mudanças tecnológicas refletem também no âmbito do lazer do adolescente. Nesta fase, jogos, computadores e celulares passam a ocupar a preferência dos jovens. Levando em consideração a predileção dos estudantes por jogos digitais e tendo em 
vista a importância da participação do aluno na construção e reconstrução do saber, o presente estudo visou apresentar um recurso alternativo para a construção do conhecimento por intermédio do uso de jogos digitais como um recurso pedagógico para o ensino de Física no nível médio da educação básica, fornecendo ao aluno um material didático concreto, lúdico, que possibilite a aprendizagem de conteúdos de física, dentro e fora da sala de aula.

Os conteúdos que foram selecionados e abordados pelo objeto de aprendizagem foram baseados em resultados obtidos em pesquisas anteriores realizadas por Krause et al (2012) e Peduzzi (2005), os quais investigaram as concepções alternativas de física presentes em alunos e professores da educação básica.

Salienta-se que o objeto de aprendizagem prototipado, buscou por meio do jogo RPG (Roleplaying Game) permitir que os estudantes, enquanto se divertem, aprendam e desenvolvam habilidades cognitivas, que podem ir desde habilidades mais simples relacionadas ao jogo, até a elaboração de raciocínios mais elaborados e tomadas de decisões.

Assim, com o intuito de verificar sua aplicação como um recurso pedagógico realizou-se uma pesquisa com os alunos do primeiro, segundo e terceiro ano do Ensino Médio de uma escola particular de Santa Rosa/RS a fim de verificar se a ferramenta construída contribuía para o aprendizado de conteúdos de física, mais especificamente conteúdos de mecânica.

\section{O PAPEL DA TECNOLOGIA NA EDUCAÇÃO}

O uso das tecnologias permite ao usuário (seja ele aluno ou professor) construir objetos virtuais, modelar fenômenos em quase todas as áreas de estudo, desenvolver a capacidade de concentração e possibilitar o estabelecimento de novas relações para a construção do conhecimento.

As escolas vivem um momento em que a disseminação das tecnologias, mais especificamente do computador no processo educativo, tem sido o catalisador de uma mudança no paradigma educacional. Com o emprego das TICs (Tecnologias de Informação e Comunicação) como ferramentas educacionais o aluno resolve problemas 
significativos. Isso pode ocorrer, por exemplo, através do uso de aplicativos como editores de textos, planilhas eletrônicas, editores de apresentações, jogos interativos e outros aplicativos correlatos que favoreçam a aprendizagem ativa, isto é, que propiciem o desenvolvimento do aluno a partir de suas próprias ações. Nessa abordagem o computador não é o detentor do conhecimento, mas um facilitador de sua construção, sendo utilizado como ferramenta que permite ao aluno o desenvolvimento cognitivo.

Neste sentido, a informática deve ser vista como um instrumento de interação com o educando, a fim de proporcionar um ambiente de aprendizagem e descoberta vivenciadas nas experiências de investigação da aprendizagem gerando o conhecimento. Portanto, os softwares educativos podem ser extremamente proveitosos se utilizados no processo experimental da aprendizagem, tendo igual importância o computador, o professor capacitado e o aluno. $\mathrm{O}$ computador, integrado às práticas de sala de aula funciona como um catalisador para a criação de ambientes de aprendizagem interdisciplinares, cujos elementos fundamentais são os autores e atores desse ambiente: os professores e os alunos. Fagundes (1997) coloca que, em ambientes de aprendizagem informatizados, com microcomputadores, ligados em rede, novas dimensões de interação são acrescentadas.

Ao trabalhar as habilidades cognitivas em cada fase de desenvolvimento da criança por meio do uso de multimídias é possível uma interação social, sendo que o software serve como uma espécie de brinquedo. Segundo Vygotsky (2003) ao brincar, o aluno está sempre acima da própria idade, acima do seu comportamento diário, maior do que é na realidade.

As ideias de Vygotsky ressaltam a importância do aprendizado que ocorre por meio de interações e jogos, permitindo que sejam criados processos de desenvolvimento e promovendo o desenvolvimento cognitivo. Para Vygotsky (2003) o jogo permite a criação de impressões para a formação de uma nova realidade que responda às exigências e inclinações dela mesma e não apenas uma recordação do que foi vivenciado.

Conforme Vygotsky (2003) o jogo pode ser um veículo para o desenvolvimento social, emocional e intelectual dos alunos, e o professor deve definir os objetivos que 
deseja alcançar com o uso de softwares educacionais e, também deve definir, quais serão as regras a serem aplicadas no momento em que esse será trabalhado, bem como explicitar como será o seu uso, para que este momento seja, de fato, significativo, atuando como mediador e promovendo o crescimento de seu aluno.

Neste sentido, Valente (1993), afirma que o uso de softwares educacionais, pode contribuir para gerar atitudes e habilidades que auxiliam o educando a conviver em sociedade.

Salienta-se, que o termo software educacional entende-se como sendo um produto orientado para uma finalidade pedagógica podendo ser aplicado em diferentes estratégias como, por exemplo, tutoriais, simulações, jogos, perguntas e respostas.

\section{O USO DE NOVAS TECNOLOGIAS E OS PROCESSOS DE APRENDIZAGEM E MEMÓRIA}

As tecnologias desenvolvidas ao longo da existência do ser humano não são apenas uma forma de se comunicar e interagir com a sociedade, mas principalmente uma forma de experimentar um mundo marcado por intensa troca de informações, rompimento de fronteiras geográficas e necessidade de trocas simbólicas. A relação com as novas tecnologias permitiu ao homem novas formas de articular e (re)construir seus pensamentos.

Segundo Perkins (1985),

De modo geral, as novas mídias (celulares, mensagens eletrônicas, livros eletrônicos, TVs interativas, jogos eletrônicos, internet, mídias sociais, dentre outras) promovem melhorias significativas nas estratégias de pensamentos já existentes, além de estimularem o surgimento de novas estratégias, sem necessariamente mudar a natureza do pensamento. (PERKINS, 1985, p. 13).

O uso de diferentes mídias, pode auxiliar no desenvolvimento de novos esquemas cognitivos que potencializam os processos de aquisição e consolidação de conhecimentos em uma sociedade onde os recursos tecnológicos surgem e se modificam a uma velocidade impressionante. Cavalheiri et al. (2013) afirmam que,

O trabalho cognitivo é o resultado da ativação de vários processos cerebrais (motivação, atenção, aprendizagem, raciocínio e memória) que estão em 
constante desenvolvimento e aperfeiçoamento, decorrentes de ações adaptativas e plásticas do sistema nervoso desde os estágios mais precoces do desenvolvimento e permanecem em constantes mudanças ao longo de toda a vida. (CAVALHEIRI ET AL., 2013, p. 09)

O uso das tecnologias de comunicação e informação estimulam a formação e alteração dos padrões neurais promovendo o desenvolvimento de funções cognitivas mais elaboradas.

\section{AS AULAS DE FÍSICA E A TECNOLOGIA}

As grandes dificuldades que afetam o Ensino de Física atualmente, se refletem principalmente na formação de indivíduos capacitados a compreender a natureza das Ciências, bem como, no entendimento dos avanços tecnológicos.

Segundo Nóvoa (2009, p.11) “a Educação vive um tempo de grandes incertezas e de muitas perplexidades. Sentimos a necessidade da mudança, mas nem sempre conseguimos definir-lhe o rumo". Para não cairmos no "efeito da moda", no grande número de textos, artigos e teses que repetem os mesmos conceitos, as mesmas ideias, as mesmas propostas, é imprescindível o domínio científico de uma determinada área do conhecimento.

Fleck (2010) nos lembra sobre a importância de questionamentos sobre o processo ensino-aprendizagem que apenas transmite aos alunos definições que são tidas como prontas, acabadas, inquestionáveis.

Assim, conforme Shulman (1986), para ser professor não basta dominar um determinado conhecimento, mas compreendê-lo em todas as suas dimensões. No momento em que traz para a sala de aula a História da Ciência o professor faz com que o aluno compreenda que a ciência não é algo dado, acabado, natural, mas uma construção. Não existe "descoberta” acidental, mas sim muito estudo por parte dos cientistas "que tanto influem como são influenciados por seu contexto físico e social" (SHEID, FERRARI; DELIZOICOV, 2005, p. 231).

O processo de ensino-aprendizagem pode ganhar assim um dinamismo, inovação e poder de comunicação inusitados desafiando o aluno a raciocinar, usando o que ele já sabe (concepções alternativas), ao mesmo tempo que exige um nível de abstração maior 
e proporciona a interação com os colegas em sala de aula despertando o prazer pela aprendizagem.

Os nativos digitais, crianças que nasceram nesse novo mundo repleto de inovação e tecnologia, incorporam mídias digitais em seu cotidiano de maneira significativa e "têm novas expectativas em relação à aprendizagem, ao trabalho e a diversão" (MATTAR, 2010, p. 11). Esses novos alunos esperam que os conteúdos sejam fáceis de compreender/aprender reutilizando imagens, ideias e expressões, criando vídeos, músicas e jogos, a fim de preencher as lacunas no entendimento. Eles "esperam se divertir ao brincar e experimentar com novas ideias e experiências, ser capazes de melhorar o seu desempenho tanto quanto e com a frequência que desejarem, e compartilhar suas expertises com o mundo tão facilmente quanto o fazem com seus amigos íntimos” (MATTAR, 2010, p. 11).

As inovações tecnológicas possibilitaram o surgimento de uma nova sala de aula e a mudança do papel docente, que passa a ser um guia dos alunos em meio à Sociedade da Informação, fazendo com que as aulas ocorram de forma mais dinâmica com maior interação entre professor aluno, onde o conhecimento não é apenas transmitido, mas construído. Isso faz com que ocorra uma mudança no currículo que também precisa ser mais dinâmico e adaptado à diversidade dos alunos.

A tecnologia tradicional utilizada nas escolas são os laboratórios de informática, separados da sala de aula. Porém, esse modelo já não é o mais adequado para um mundo cada vez mais conectado como o nosso, onde as tecnologias fazem parte da nossa vida cotidiana. O caminho seria estas novas tecnologias serem levadas para dentro da sala comum e utilizadas integradas a ela, de modo que a escola não signifique um distanciamento da vida real dos alunos.

A escola sempre assimilou os novos suportes disponíveis para a potencialização da ação didática. Em uma sala de aula digital, as novas tecnologias abrem novas possibilidades de trabalho.

As fronteiras entre aprendizagem, trabalho e diversão estão desaparecendo, tornando necessário que educadores e instituições de ensino repensem seus métodos. “As experiências com mídias digitais fazem parte de uma transformação cultural mais 
ampla que está simultaneamente moldando-os e proporcionando-lhes um novo meio para criatividade e participação" (MATTAR, 2010, p. 11).

Assim como assimilamos conhecimentos através de atividades práticas precisamos desde cedo desenvolver as chamadas competências e habilidades digitais através do uso de ferramentas adequadas. O que ocorre na sala de aula sempre foi apoiado por tecnologias, pois as práticas educacionais como aulas expositivas, exercícios, leitura e pesquisa, entre outras atividades didáticas, necessitam do suporte de tecnologias já tradicionais nas escolas, como o quadro-negro, lápis, cadernos e livros. Como vivemos em uma cultura digital, fica claro que as habilidades e competências requeridas em nossa sociedade só podem ser desenvolvidas através de atividades com o uso de tecnologias digitais.

Conforme Mattar (2010) a educação de nossos jovens está segmentada entre o ambiente escolar, onde o conteúdo é descontextualizado e deve ser decorado de forma passiva e individualmente; e os games, que permitem o aprendizado em simulações que o próprio jogador ajuda a construir ativa e colaborativamente.

A sociedade atual permite aos jovens aprender a qualquer hora e em qualquer lugar, e estes se tornam cada vez mais resistentes a cultura da transmissão de conhecimento dos mais velhos para os mais novos. Os jogos permitem aprender em um ambiente em que não há pressão e envolvem diversos fatores cognitivos, culturais, sociais, afetivos, etc.

O uso de games como ferramentas no processo de ensino permite o desenvolvimento de habilidades nos alunos e faz com que o professor atue mais como "diretor de pesquisa e treinador do que um palestrante e disciplinador" (MATTAR, 2010, p.20).

Os jogos contribuem para o Ensino das Ciências na medida em que unem o prazer e a satisfação ao ensino e a aprendizagem, oferecendo inovação ao ambiente escolar. Segundo Balestra e Gequelin (2008) os jogos são recursos pedagógicos que permitem a construção do conhecimento, aumentando a motivação para aprender, desenvolver a autoconfiança, a capacidade de organização, a imaginação, a concentração, a atenção, o raciocínio lógico-dedutivo e, a sociabilidade. Além disso, estimulam a comunicação e o 
trabalho em equipe, facilitam a aquisição de novos conhecimentos, proporcionam experiências, desenvolvem o aspecto físico e mental e estimulam a procura por alternativas para solucionar problemas.

Vigotsky (2003) categoriza os jogos em três grupos. O primeiro formado por brincadeiras com diferentes objetos, como chocalhos, lançar e recuperar objetos, permitindo a criança aprender a ver, ouvir e segurar. O segundo grupo de jogos relaciona-se à elaboração de habilidades de se deslocar no ambiente. E por fim, o terceiro grupo é denominado jogos com regras em que as crianças organizam formas superiores do comportamento que geralmente estão ligadas à resolução de problemas e exigem do jogador análise, compreensão, sagacidade e criatividade.

Os jogos de regras exercitam no aluno a capacidade de planejar, imaginar situações diversas, representar papéis e situações do cotidiano, compreender o caráter social das situações lúdicas, analisar e assimilar os seus conteúdos e as regras inerentes à cada situação.

Conforme Vygotsky (2003) existem dois elementos importantes no ato de jogar: a situação imaginária e as regras. Logo, é possível observar a coordenação de experiências reproduzidas através do jogo e a aplicação de conhecimentos que os alunos já trazem consigo através de uma situação imaginária. Para o autor a ação que estabelece regras desperta novas ideias.

Chateau (1987) enfatiza que os jogos de regras auxiliam no desenvolvimento de aspectos cognitivos, despertam a atenção, o senso de responsabilidade e o senso crítico, despertam noções de sociedade e cumprimento de regras, além de desenvolver "aspectos morais como autonomia e cooperação, sendo de extrema importância que o educador integre a criança na sociedade de forma lúdica, dinâmica e completa através da interação desta com o meio físico, social, cultural, afetivo, entre outros". (CHATEAU, 1987, p. 72).

O professor, ao utilizar-se de situações desafiadoras para promover e avaliar o processo ensino-aprendizagem está possibilitando ao aluno uma aprendizagem mais prazerosa e interessante, finaliza Balestra e Gequelin (2008). Cabe lembrar que são necessárias práticas de formação do professor, de modo a aproximar os docentes desses 
novos ambientes de aprendizagem, fazendo com que estes se apropriem deles ressignificando-os e trazendo-os para dentro da escola.

\section{OS JOGOS E A SUA RELAÇÃO COM A FÍSICA}

Os jogos podem ser usados de diferentes maneiras na educação, como meio para transmitir a informação ao aluno, e como uma maneira de informatizar os métodos tradicionais de instrução. Seu uso na educação trás o desafio de que o conteúdo educacional aliado a um objeto de aprendizagem pode estimular e motivar os alunos tanto quanto os games comerciais.

Para atingir esse objetivo, conforme Kishimoto (1994), os jogos devem agregar valores experimentais, de estruturação, relação e lúdico:

- O valor experimental: permitir a exploração e manipulação.

- O valor da estruturação: dar suporte à construção da personalidade infantil.

- O valor da relação: colocar a criança com seus pares e adultos, com objetos e com o ambiente em geral para propiciar o estabelecimento de relações.

- O valor lúdico: avaliar se os objetos possuem qualidades que estimulem o aparecimento da ação lúdica. (KISHIMOTO, 1994, p. 63).

$\mathrm{Na}$ proposta de uso de games no ensino da Física, o papel do professor é de mediador que orienta as interações do aluno preservando o equilíbrio entre o ato pedagógico e o lúdico. O objetivo da interação com jogos é colocar o aprendiz em situação de desafio proporcionando um envolvimento com a atividade e fazendo com que este busque um entendimento maior do conteúdo. Em um processo simples os alunos aprendem conceitos importantes para o aprendizado da Física.

Dentro do processo de construção/ reconstrução do conhecimento, a utilização de jogos nas aulas de Física pode auxiliar o aluno a interagir, refletir, visualizar, verificar suas teorias e concepções alternativas, desenvolvendo habilidades e buscando a autonomia na construção de conhecimentos. 
Os jogos proporcionam a inter-relação do conhecimento inicial e espontâneo que o aluno possui em situações onde são trabalhados os conceitos físicos ditos formais. Diante das dificuldades encontradas pelos estudantes em ligar a física da sala de aula a situações do dia-a-dia, faz-se necessário pensar na utilização de recursos pedagógicos que auxiliem a integrar os conhecimentos físicos espontâneos que o aluno traz consigo construídos no seu cotidiano, aos conhecimentos físicos curriculares, a fim de que se torne possível sua compreensão e ampliação.

Segundo as avaliações realizadas pelo $\mathrm{MEC}^{1}$, os alunos apresentam baixo desempenho na disciplina de Física e, daí vem a importância de se pensar no jogo como estratégia de ensino e aprendizagem e como uma alternativa atraente de trabalhar o conteúdo em sala de aula, de forma a possibilitar que o aluno seja um sujeito ativo e construa seu conhecimento na inter-relação com outros sujeitos.

Black e Wiliam (2000) utilizam a expressão "avaliação formativa" como referência a todas as atividades empreendidas por professores e seus alunos que forneçam informação usada como feedback para modificar as atividades de ensino e de aprendizagem. Para eles, o trabalho do professor deve "livrar os alunos da armadilha do baixo rendimento" e desenvolver "hábitos necessários para todos os alunos se tornarem aprendizes para toda a vida".

Segundo Balestra e Gequelin (2008) no contexto dos jogos o aluno evolui na aquisição de conhecimentos ao superá-lo, porque gradativamente vai adquirindo uma compreensão de todo o contexto ao identificar e corrigir determinadas falhas durante o jogo além de adquirir autonomia ao superar o erro, quando encontra formas de corrigilo.

Conforme Nasser (2006) um jogo em uma aula de Física quebra sensivelmente a rotina e traz para a sala um ar de ludicidade pouco comum nas aulas dessa disciplina. Possibilitar situações de jogo para o aluno pode representar uma estratégia significativa para aproximá-lo dos conteúdos sistematizados propostos pela escola, e, além disso, promover o desenvolvimento de novas estruturas cognitivas.

\footnotetext{
${ }^{1}$ Ministério de Educação e Cultura
} 
Proporcionar prazer e diversão, representar um desafio e despertar o pensamento reflexivo do aluno, são algumas razões para que o jogo seja utilizado no ensino da Física. Daí a importância da elaboração de instrumentos que estimulem o interesse do aluno em conhecer o mundo físico e suas leis, a partir de experimentos essenciais para o desenvolvimento da autonomia intelectual necessária ao exercício da cidadania.

O ensino de Física deve ser entendido como fundamental na formação de pessoas que lidam com tecnologias cada vez mais avançadas, sem conhecer seu princípio básico de funcionamento, tratando-os como se fossem 'caixas mágicas'. "Quando levamos nossos alunos a refletir sobre os problemas experimentais que são capazes de resolver, ensinamos-lhes, mais do que conceitos pontuais, a pensar cientificamente o mundo, a construir uma visão de mundo" (CARVALHO, 1998, p. 25).

\section{RPG - ROLEPLAYING GAME}

Os professores encontram grandes dificuldades em motivar os estudantes para a rotina educacional de sala de aula, uma vez que em um mesmo ambiente são encontradas diferentes demandas e diversos interesses dos alunos e suas especificidades em relação ao saber. O uso de músicas, vídeos e atividades diferenciadas em laboratório não é mais suficiente para atender as expectativas de uma turma de alunos que, em meios aos recursos tecnológicos, realizam outras atividades em detrimento daquela solicitada.

O Roleplaying Game (RPG) significa Jogo de Interpretação de Papéis e é um game de contar histórias que pode ser usado por jovens e adultos. Ele surge como um instrumento pedagógico capaz de ser adaptado ao interesse de cada estudante atendendo as suas particularidades e "envolvendo-os num processo de ensino que permita uma participação de acordo com as condições de aprendizagem de cada um." (AMARAL; BASTOS, 2011, p. 02).

Segundo Amaral (2008) além do RPG tradicional existe o RPG digital, que consiste em jogos de estratégia pelo computador, e o card game que é um jogo de cartas baseado nas regras do RPG. Independentemente da versão, o game abre novas perspectivas de aplicação e resolução de problemas do mundo real. 
Os jogos e brincadeiras em sala de aula prendem a atenção do aluno. No entanto, para ser considerada lúdica uma atividade deve apresentar indicadores como: prazer funcional, apresentação de desafios e surpresas, criação de possibilidades, possuir dimensão simbólica e expressão construtiva ou relacional. (MACEDO; PETTY; PASSOS, 2005).

Para atender esses objetivos o RPG faz uso de cenários, personagens, sistema de regras que delimita os personagens dentro do universo ficcional escolhido, como suas características e o resultado de suas ações. "Não importa se a ambientação se aproxima o quanto possível da realidade, ou oferece um cenário totalmente fantástico, o importante é que os dados sejam verossímeis, que se criem possibilidades condizentes com este universo ficcional” (VASQUES, 2008, p. 24).

No RPG as histórias são narradas e se modificam conforme as ações dos personagens que tem liberdade para agir na história. Conforme Vasques "o narrador não tem o controle sobre as decisões tomadas pelos personagens dos jogadores. Mesmo que ele possa tentar prever algo os jogadores sempre terão a possibilidade de pensar em soluções não imaginadas pelo narrador" (VASQUES, 2008, p. 28).

Assim, as características apresentadas pelo RPG são condizentes com a sociedade moderna permitindo a sistematização de dados, o uso de raciocínio lógico e o pensamento voltado para a resolução de problemas do interesse de todos através da colaboração entre os participantes.

\section{MODELAGEM E PROTOTIPAÇÃO DO OBJETO DE APRENDIZAGEM}

A pesquisa desenvolvida fundamenta-se na abordagem qualitativa e está sendo caracterizada como aplicada (GIL, 2010) porque está preocupada com a utilização imediata do seu resultado e consequência da sua utilização na prática, a qual relacionase com a aplicabilidade do produto tecnológico produzido que no caso especifico foi a construção de um jogo de RPG em 2D. 
Para o desenvolvimento do jogo seguiu-se as etapas de desenvolvimento da estória, desenvolvimento das regras (manual do jogo), criação dos personagens e desenvolvimento do objeto de aprendizagem.

O desenvolvimento da estória foi baseado no Desenho "A Caverna do Dragão" e na Aventura "A Tumba do Rei Esquecido", história do RPG Mighty Blade, do autor Tiago Junges. Existem muitos RPGs no mercado, e estes são separados por Sistemas (conjunto de regras) para ajudar os jogadores a entender o que está acontecendo com seus personagens e qual será o resultado de suas ações. O Mighty Blade é um sistema de RPG simples para jogadores iniciantes.

A história criada para o jogo proposto por esse estudo chama-se a Caverna do Dragão - A Aventura na Tumba do Rei. A imagem da Figura 1 traz o cenário inicial do jogo.

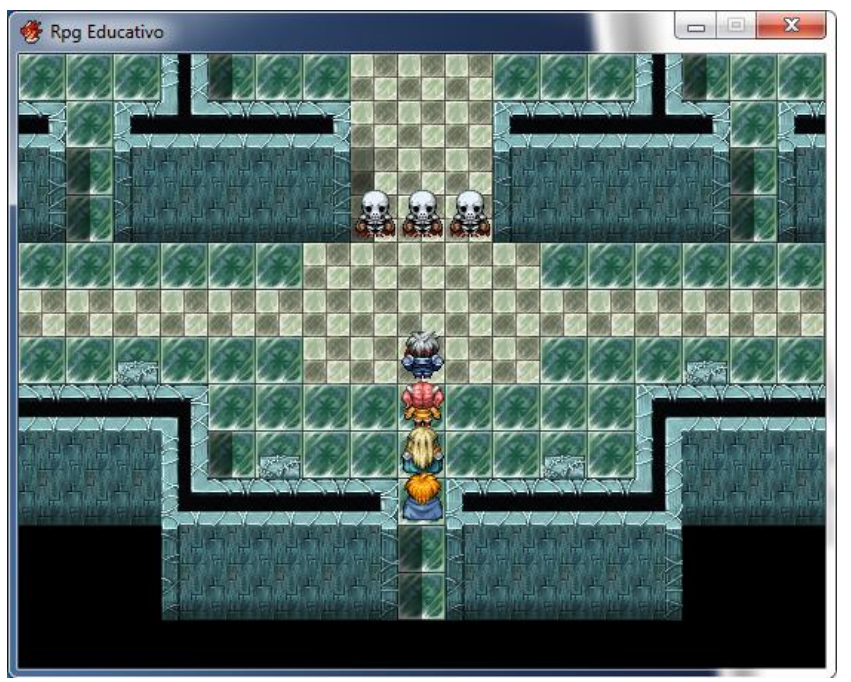

Figura 1: Visão dos personagens no cenário (FELBER, 2015).

As regras foram desenvolvidas determinando a Ficha do Personagem, Testes de inteligência realizados através de questões de Físicas (Figura 2), combates, pontos de vida dos personagens e suas habilidades. 


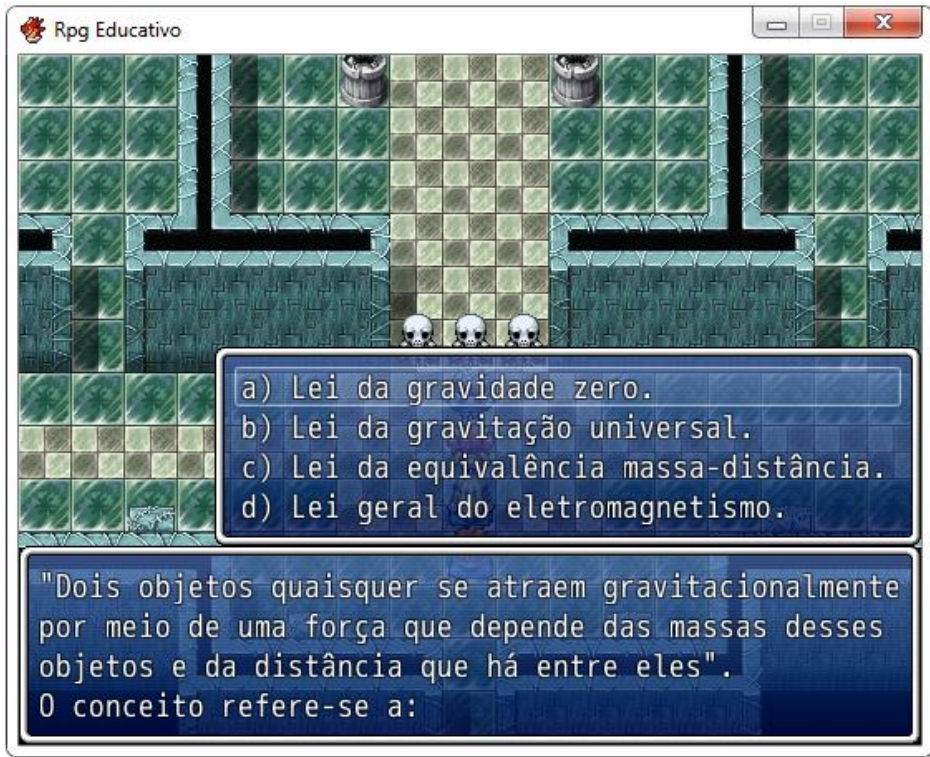

Figura 2: Visão das perguntas durante o jogo (FELBER, 2015).

O desenvolvimento da ferramenta ocorreu por intermédio do software RPG Maker, usado para criar jogos de RPG em 2D, e é um software gratuito. O RPG Maker possui uma diversidade de recursos que permitem a construção de um jogo eletrônico onde o papel do mestre da partida é desempenhado pelo próprio jogo já construído.

Concluída a etapa de elaboração/construção do jogo, o mesmo foi aplicado para alunos do Ensino Médio de uma escola particular no município de Santa Rosa/RS.

\section{MÉTODOS E COLETA DE DADOS}

Foram sujeitos da pesquisa 94 alunos dos três anos do Ensino Médio de uma escola particular de Santa Rosa/RS. Os sujeitos da pesquisa eram de ambos os gêneros, que espontaneamente aceitaram fazer parte da pesquisa após a assinatura do Termo de Assentimento, Livre Esclarecido.

O estudo foi realizado conforme os aspectos éticos contidos na resolução 466, de 12 de dezembro de 2012 do Conselho Nacional de Saúde, que trata da pesquisa envolvendo seres humanos. A pesquisa foi aprovada perante o Comitê de Ética em Pesquisa da Universidade Regional Integrada do Alto Uruguai e das Missões, sob o parecer número 745.868 . 
Para cada turma, inicialmente foi apresentada a estória do jogo, explicando os detalhes e as regras, bem como o ambiente e o objetivo do desenvolvimento da ferramenta. Para que os alunos se sentissem a vontade para responder a pesquisa proposta por este estudo, os alunos foram estimulados a interagir com o jogo por um tempo determinado, suficiente para interagir com todas as etapas/fases do jogo.

Após a interação com o jogo, os alunos foram solicitados a responder um questionário anonimamente com questões abertas/fechadas. As questões tratavam sobre: 1) Qual a maior dificuldade que você encontrou em relação ao Ensino da Física? 2) Você já participou desse tipo de experiência? 3) Qual a sua percepção quanto ao jogo aplicado? 4) Qual a sua visão sobre o uso do jogo no Ensino da Física? 5) O que você achou das regras do jogo aplicado? 6) O que mais chamou a sua atenção no jogo "A Caverna do Dragão - A Aventura na Tumba do Rei’? 7) Depois da aplicação do jogo houve alguma mudança na sua concepção a respeito do ensino de Física? 8) Você gostaria que o professor de Física adota-se o uso de jogos didáticos para auxiliar no processo de ensino-aprendizagem?

\section{MÉTODOS E COLETA DE DADOS}

Foram sujeitos da pesquisa 94 alunos dos três anos do Ensino Médio de uma escola particular de Santa Rosa/RS. Os sujeitos da pesquisa eram de ambos os gêneros, que espontaneamente aceitaram fazer parte da pesquisa após a assinatura do Termo de Assentimento, Livre Esclarecido.

O estudo foi realizado conforme os aspectos éticos contidos na resolução 466, de 12 de dezembro de 2012 do Conselho Nacional de Saúde, que trata da pesquisa envolvendo seres humanos. A pesquisa foi aprovada perante o Comitê de Ética em Pesquisa da Universidade Regional Integrada do Alto Uruguai e das Missões, sob o parecer número 745.868 .

Para cada turma, inicialmente foi apresentada a estória do jogo, explicando os detalhes e as regras, bem como o ambiente e o objetivo do desenvolvimento da ferramenta. Para que os alunos se sentissem a vontade para responder a pesquisa 
proposta por este estudo, os alunos foram estimulados a interagir com o jogo por um tempo determinado, suficiente para interagir com todas as etapas/fases do jogo.

Após a interação com o jogo, os alunos foram solicitados a responder um questionário anonimamente com questões abertas/fechadas. As questões tratavam sobre: 1) Qual a maior dificuldade que você encontrou em relação ao Ensino da Física? 2) Você já participou desse tipo de experiência? 3) Qual a sua percepção quanto ao jogo aplicado? 4) Qual a sua visão sobre o uso do jogo no Ensino da Física? 5) O que você achou das regras do jogo aplicado? 6) O que mais chamou a sua atenção no jogo "A Caverna do Dragão - A Aventura na Tumba do Rei”? 7) Depois da aplicação do jogo houve alguma mudança na sua concepção a respeito do ensino de Física? 8) Você gostaria que o professor de Física adota-se o uso de jogos didáticos para auxiliar no processo de ensino-aprendizagem?

\section{RESULTADOS E DISCUSSÃO}

Uma leitura atenta dos questionários permitiu nortear questões centralizadoras relacionadas as maiores dificuldades encontrada pelos estudantes em relação ao Ensino da Física, conforme demostra a Figura 3. Percebe-se que a maioria dos alunos (quase $45 \%$ ) destacam que a metodologia utilizada pelo professor seria a principal causa de suas dificuldades com esta disciplina.

A segunda maior dificuldade citada pelos alunos foi a falta de interesse pela disciplina (20,21\%), entende-se assim que o jogo apresentado surge como complemento para as aulas tradicionais contribuindo para a motivação do estudante. 


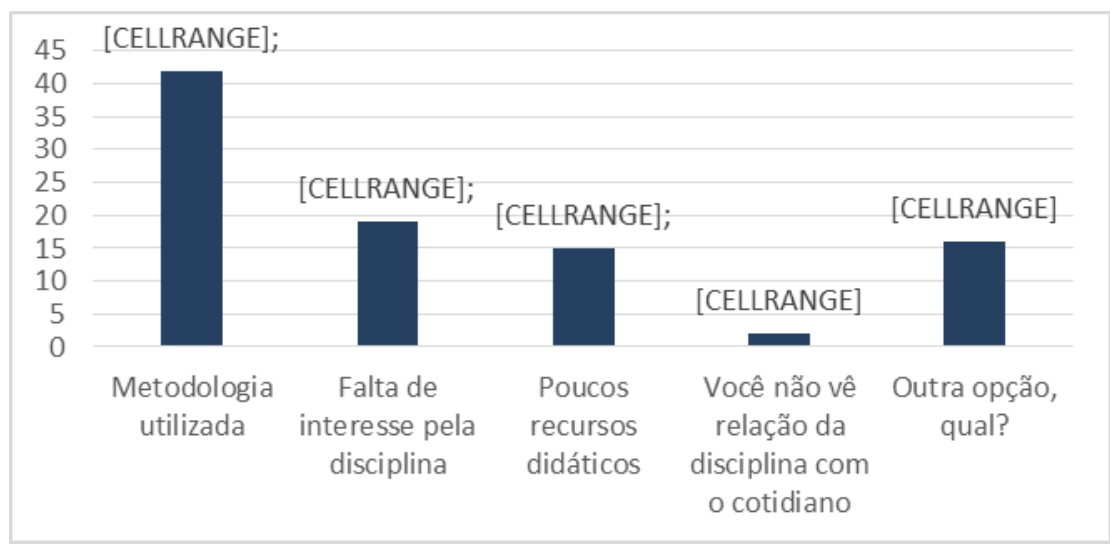

Figura 3: Dificuldades em relação a Física (FELBER, 2015).

Com relação a questão que solicitou se o aluno já havia participado de atividades envolvendo jogos didáticos a maioria dos estudantes, cerca de $73,4 \%$, respondeu que ainda não haviam participado de atividades baseadas em jogos didáticos em sala de aula, Neste sentido, considera-se que o RPG é um auxiliar para tornar os conteúdos mais atraentes e proporcionar uma atividade exploratória e lúdica, estimulando a comparação e diferenciação, além de exigir sua atenção e organização do pensamento e da ação. Valente (2002) destaca que no momento que a educação passa por um processo de renovação e as mudanças tecnológicas vem estabelecendo mudanças nos métodos tradicionais de ensino, surge a necessidade de utilizar recursos que motivem os alunos remodelando os métodos tradicionais de ensino.

Em relação a percepção dos alunos sobre os jogos, a grande maioria dos alunos participantes da pesquisa $(93,62 \%)$, considerou o uso do jogo interessante e divertido. Uma pequena parcela, apenas 4,26\%, considerou que a utilização do RPG na sala de aula não teve diferenças com relação as aulas normais. No que se refere a presença de jogos em sala de aula, 97,87\%, consideram que o RPG foi uma forma prazerosa e motivadora de se aprender conceitos Físicos. Assim, considera-se o RPG como um recurso tecnológico auxiliar que permite a realização da aprendizagem de forma mais criativa, libertando-se do convencional e gerando novas formas de organização do processo de ensino e aprendizagem.

Com relação as regras do jogo, a maioria dos estudantes $(81,91 \%)$ considerou as regras do jogo de fácil entendimento, conforme demostra a Figura 4. 
Já o que mais chamou a atenção dos alunos em relação ao jogo, foi a forma divertida de aprender física (67,02\%). Alguns consideraram o jogo em si $(23,4 \%)$ e poucos destacaram a interação com o grupo (9,57\%). Segundo Amaral e Bastos (2011) o jogo, com seu caráter lúdico, torna o conteúdo mais atrativo ao aluno contrapondo-se à ideia de algo chato ou entediante. Considera-se que os aspectos do jogo, como a sensação de aventura por ele proporcionada, estimula a participação de todos os alunos, pois dentro de uma mesma sala de aula podem ser encontrados estudantes com diferentes dificuldades.

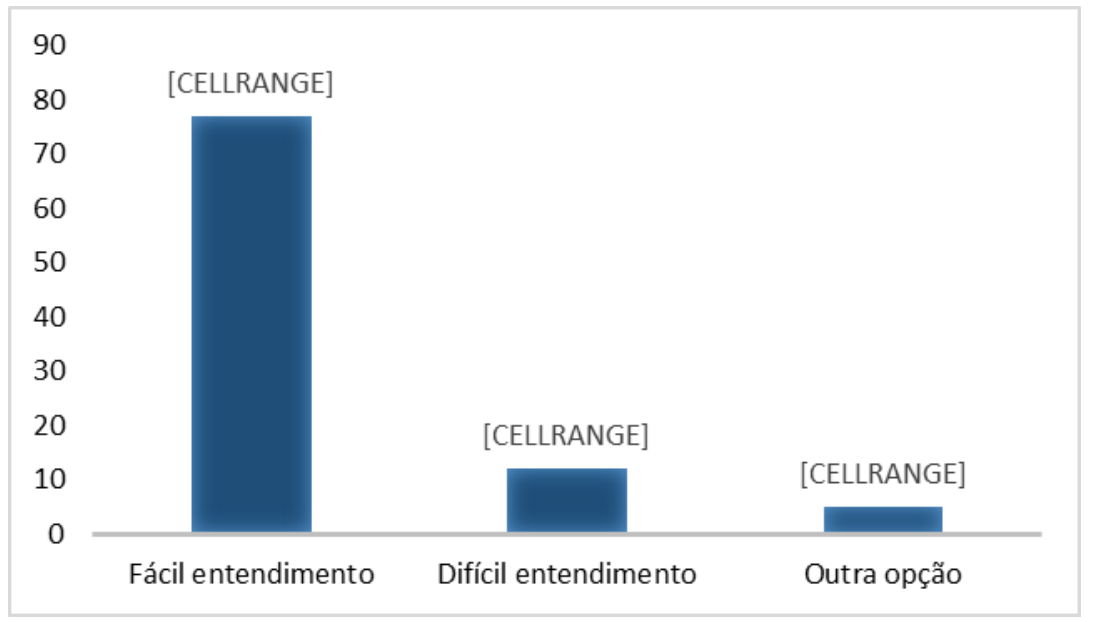

Figura 4: Regras do Jogo (FELBER, 2015).

Verificou-se também se o jogo representou para os alunos alguma mudança quando utilizado como recurso pedagógico para o ensino da Física (Figura 5). A maior parte dos alunos $(73,4 \%)$ considerou que o RPG melhorou a sua compreensão de conceitos físicos. Alguns alunos $(21,28 \%)$ consideraram que o RPG era apenas um jogo. 


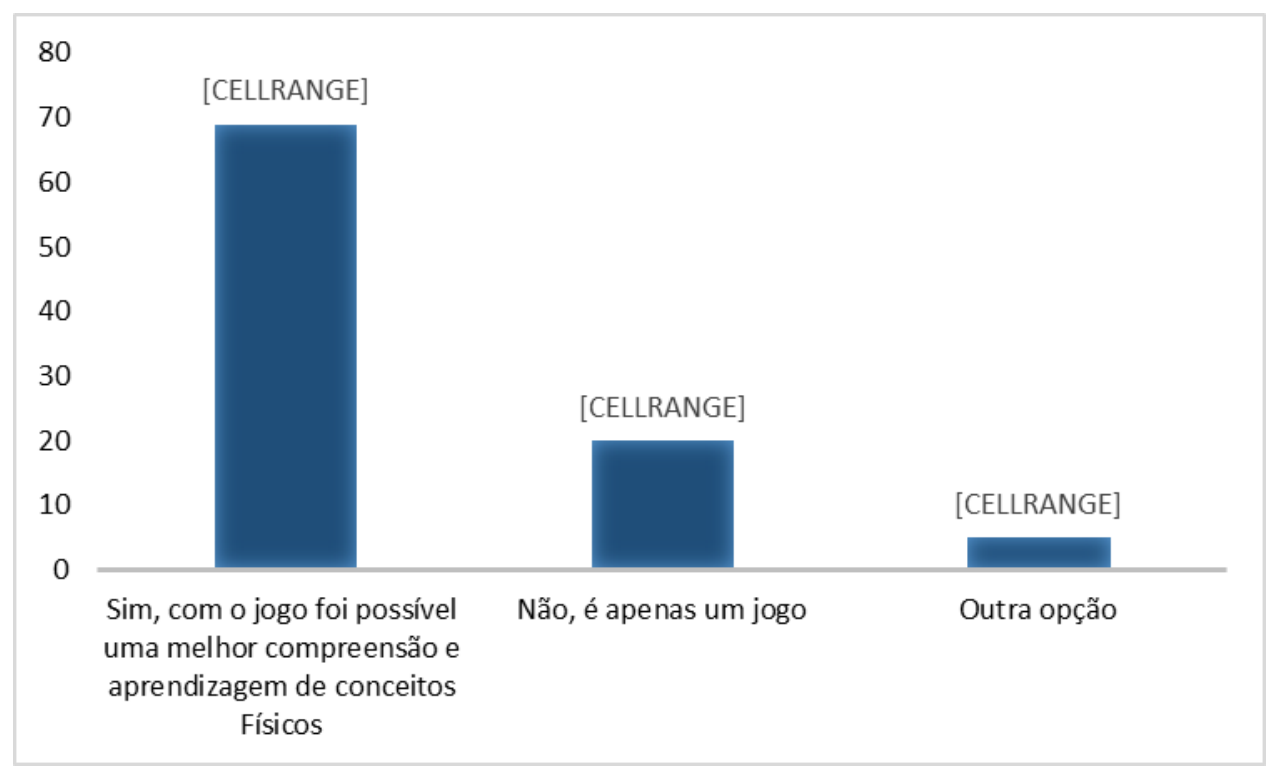

Figura 5: Mudança de concepção (FELBER, 2015).

Com relação ao desejo dos alunos de que esta estratégia fosse utilizada mais vezes no auxílio do processo de ensino, a maioria $(98,94 \%)$ dos participantes demostrou interesse no uso de jogos, afirmando que estes auxiliam no processo de ensino. Neste sentido o professor tem papel fundamental nesse processo, uma vez que, ele permite conhecer e avaliar melhor o aluno proporcionando avanços em sua aprendizagem e desenvolvimento.

Quanto a percepção geral sobre o uso do jogo (Figura 6), a maioria dos participantes da pesquisa $(64,89 \%)$ afirmou que o uso do jogo permitiu que o professor expusesse melhor o assunto, "quebrando" a rotina das aulas expositivas e tradicionais, auxiliando no processo de aprendizagem do conteúdo. Em segundo lugar (19,15\%), os alunos afirmaram que o uso do RPG na aula fez com que ela fosse mais proveitosa uma vez que possibilitou através do jogo uma melhor comunicação entre alunos e professor. Em terceiro lugar, 10,64\% dos alunos participantes afirmaram entender claramente o que estava sendo proposto pelo professor, aprendendo o assunto explicado e consideraram a aula dinâmica e demonstrativa. Considerando estas respostas, pode-se concluir que o RPG permite ao professor interagir com o grupo de alunos percebendo as dificuldades de cada um e possibilitando a identificação de estratégias que auxiliem na resolução de problemas e na melhor absorção do conteúdo por parte do educando. 


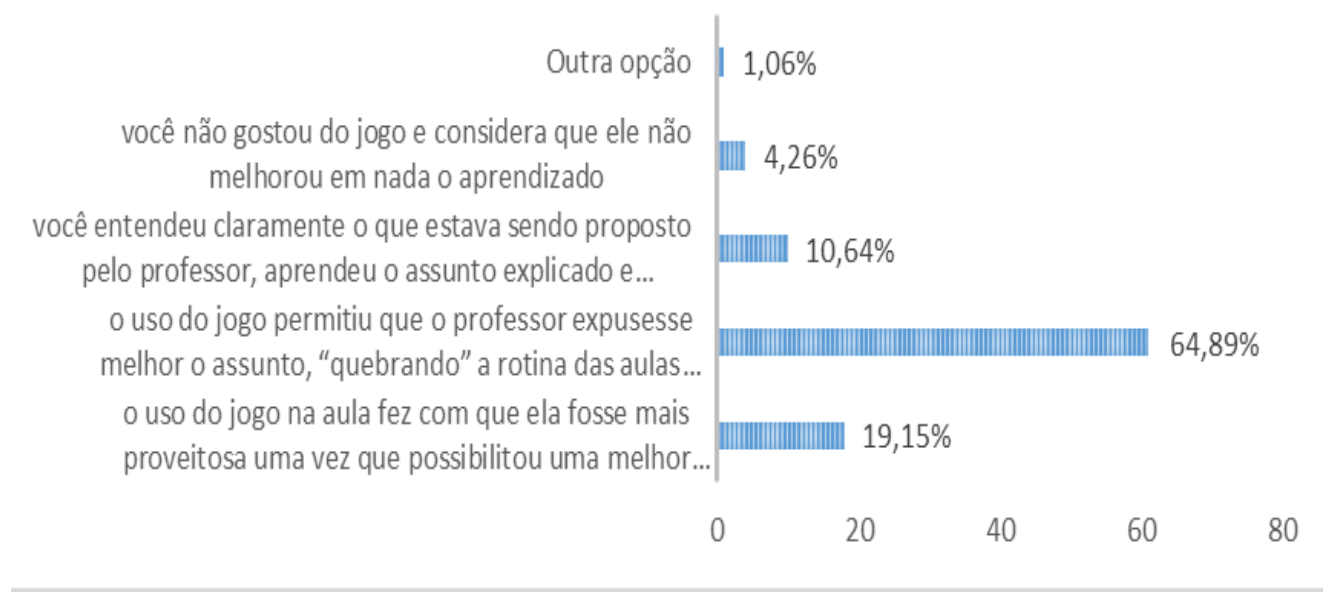

Figura 6: percepção geral sobre o uso do jogo (FELBER, 2015).

Considerando os resultados anteriormente apresentados percebe-se que os estudantes em sua maioria $(<84 \%)$ gostaram do jogo e consideraram o uso do jogo como um recurso que agrega diversão e interação em sala de aula, permitindo que os saberes trabalhados no Ensino da Física sejam expressos através de uma linguagem diferente que estimula e explora as potencialidades dos educandos. Uma pequena minoria dos estudantes $(4,26 \%)$ não gostou do jogo e consideraram que ele não melhorou em nada o aprendizado, talvez por não terem uma maior intimidade com as tecnologias digitais. Com relação as regras do jogo, a maioria achou de fácil entendimento.

Assim, pode-se perceber que os estudantes consideram o uso do jogo como um recurso que agrega diversão e interação em sala de aula, permitindo que os saberes trabalhados no Ensino da Física sejam expressos através de uma linguagem diferente que estimula e explora as potencialidades dos educandos. Além disso, é possível explicar as particularidades dos integrantes do grupo através da interação com o professor que participa como mediador da atividade.

Dessa foram, o RPG pode ser utilizado como ferramenta pedagógica para o ensino da Física na medida que proporciona uma maior relação social entre os jogadores. Segundo Rocha além das amizades e do convívio social que ele proporciona, "durante 
as observações das atividades dos grupos de jogo verificou-se que, de fato, a dinâmica do jogo, a forma como o jogo acontece pode contribuir para o desenvolvimento das habilidades ligadas à capacidade de interação social” (ROCHA, 2006, p. 91). O jogo permite aqueles que interagem com ele passar por situações que exigem capacidade de argumentação e interação social, o que ocorre através da situação vivenciada pelo personagem.

É imperativo destacar que o game foi capaz de estimular nos jogadores o raciocínio lógico e permite a aprendizagem de conhecimentos de Física ao mesmo tempo que promove diversão.

\section{CONSIDERAÇÕES FINAIS}

Diante dos resultados da investigação foi possível perceber que é fundamental o docente utilizar estratégias pedagógicas que auxiliem e despertem o interesse do aluno ao aprendizado.

Tendo em vista as dificuldades encontradas pelos professores em motivar os alunos no Ensino da Física, o uso do Roleplaying Game (RPG) enquanto recurso pedagógico, possibilita atender a diferentes demandas de uma sala de aula, contemplando os diversos interesses dos alunos e suas especificidades em relação ao saber.

Assim, o RPG pode auxiliar os educandos a absorver conhecimentos de Física e, ao mesmo tempo que estimula, permitir a cooperação quando jogado em equipe, melhorando as relações sociais. A ferramenta tem potencial lúdico visto que os jogadores podem viajar, através da mente, vivendo aventuras em outros ambientes, no passado ou futuro, muitas vezes possíveis apenas pelo poder criativo de suas imaginações. Ao mesmo tempo o jogo conduz a diversão com a aventura vivenciada durante o jogo.

Além disso, o uso do game permite a aprendizagem através de estímulos emotivos e relações mais próximas com os conceitos estudados. Segundo Vasques (2008), para que isso ocorra o aprendizado deve ser realizado com prazer atendendo a dois critérios básicos: utilidade (seja imediata ou posterior) e fonte de satisfação e prazer. Ele também 
atende ao critério de auxiliar o educando a lidar com regras, o que o prepara melhor para o convívio em sociedade. O uso de jogos e brincadeiras na sala de aula, motiva os alunos pela aprendizagem de conteúdo, o que se tornou claro durante a aplicação da ferramenta. Ela apresentou alguns indicadores como: prazer funcional, apresentar desafios e surpresas, criação de possiblidades, possuir dimensão simbólica e expressão construtiva ou relacional, que segundo Macedo, Petty e Passos (2005) são essenciais em uma atividade lúdica.

O desenvolvimento do jogo (RPG) no ensino de Física trouxe para a sala de aula um material específico e, após sua prototipação foi além do proposto no projeto inicial, agregando a aula uma atividade e um conteúdo interativo, e abrindo a possibilidade de desenvolvimento de novas histórias, para estudo dos diversos conteúdos de Física durante as diferentes séries do Ensino Médio. Esse jogo, em específico, buscou abordar conteúdos de mecânica ficando restrito as Leis de Newton e abrindo possibilidade para posterior aplicação nos demais conteúdos de Física.

Desta forma, este estudo permitiu identificar o jogo como recurso pedagógico que aproxima o aprendizado da realidade sociocultural do aluno. Conclui-se assim, que os objetivos propostos foram plenamente atingidos e, este trabalho deixa como contribuição, o uso de jogos aliados aos conteúdos de Física contribuindo assim no desenvolvimento de um processo de aprendizagem significativa em um mundo onde a tecnologia está em constante evolução.

\section{REFERÊNCIAS}

AMARAL, Ricardo Ribeiro do. BASTOS, Heloisa Flora Brasil Nóbrega. O Roleplaying Game na sala de aula: uma maneira de desenvolver atividades diferentes simultaneamente. Revista Brasileira de Pesquisa em Educação em Ciências, v. 11, n. 1, p. 103-122, 2011.

AMARAL, Ricardo Ribeiro do. Uso do RPG pedagógico para o ensino de física. 2008. 170 f. 2008. Dissertação (Mestrado em Ensino das Ciências) - Universidade Federal Rural de Pernambuco, Recife. 
BITtencourt, J. R.; GIRAFFA, L. M. Modelando Ambientes de Aprendizagem Virtuais utilizando Role-Playing Games. 2003. Disponível em: <http://www.nce.ufrj.br/sbie2003/publicacoes/paper71.pdf>. Acesso em: 21 set. 2017.

BLACK, P.; WILIAM, D. Inside the Black Box: raising standards through classroom assessment. London: School of Education, King's College, 1998.

BORBA, M.; PENTEADO, G. Informática e Educação Matemática. Autêntica: Belo Horizonte, 2001.

CARVAlhO, A.M.P. et al. Ciências no Ensino Fundamental. São Paulo: Ed. Scipione, 1998.

CAVILHEIRI, Alceu; ENGERROFF, Sérgio N.; SILVA, Jolair da Costa. As Novas Tecnologias e os Desafios para uma Educação Humanizadora. Santa Maria: Biblos, 2013.

FLECK, Ludwik. Gênese e desenvolvimento de um fato científico: introdução à doutrina do estilo de pensamento e do coletivo de pensamento. Belo Horizonte: Fabrefactum, 2010.

CHATEAU, Jean. O jogo e a criança. São Paulo: Summus, 1987.

FREIRE, Paulo. Pedagogia do Oprimido. 17 ed. Rio de Janeiro: Paz e Terra, 1987.

GIL, Antônio Carlos. Como elaborar projetos de pesquisa. 4. ed. São Paulo: Atlas, 2002.

KRAUSE, J. C.; SANTOS, A. V. dos; SANDRI, H. Concepções Alternativas Sobre Física Básica Em Professores Da Região De Santo Ângelo-Rs. In: SIMPÓSIO DE ENSINO DE FÍSICA E MATEMÁTICA, 2., Santa Maria: Unifra, 2012.

KISHIMOTO, Tizuco M. O Jogo e a Educação Infantil. São Paulo: Ed. Pioneira, 1994.

LEMES, David de Oliveira. Games Independentes: Fundamentos metodológicos para criação, planejamento e desenvolvimento de jogos digitais. São Paulo: PUC-SP, 2009.

LÈVY, Pierre. As tecnologias da Inteligência - o futuro da inteligência coletiva na era da informática. São Paulo: Ed. 34, 1993. 
MACEDO, Lino de; PETTY, Ana Lúcia Sícoli; PASSOS, Norimar Christe. Os jogos e o lúdico na aprendizagem escolar. Porto Alegre: Artmed, 2005.

MATTAR, João. Games em educação: como os nativos digitais aprendem. São Paulo: Pearson Prentice Hall, 2010.

NASSER, Pedro Zille Teixeira. Jogos em aulas de física: uma experiência didática. Monografia (Licenciatura) - Universidade do Estado do Rio de Janeiro, Instituto de Física, 2006.

NÓVOA, António. Professores: Imagens do futuro presente. Lisboa: Educa, 2009.

PEDUZZI, S. S. Concepções Alternativas em Mecânica. In: PIETROCOLA, Maurício (Org.). Ensino De Física: Conteúdo, metodologia e epistemologia em uma concepção integradora. 2. ed. Florianópolis: Editora da Ufsc, 2005. p. 53-75.

PERKINS, D. N. The fingertip effect: How information processing technology changes thinking. Educational Researcher, v. 14, n. 7., p. 11-17, 1985.

RABELO, Cláudio. Game Design. Desenvolvimento de jogos 3D e aplicações em realidade virtual. Rio de Janeiro: Elsevier, 2005.

VALENTE, José Armando. Diferentes usos do computador na educação. In Computadores e conhecimento: repensando a educação. 2 Ed. Campinas: Universidade Estadual de Campinas - UNICAMP, 1998.

VASQUES, Rafael Carneiro. As potencialidades do RPG (Role Playing Game) na Educação Escolar. 2008. Tese de Doutorado. Dissertação (Mestrado em Educação Escolar) Departamento de Didática, Programa de Pós-Graduação em Educação Escolar da Unesp - Universidade Estadual Paulista “Júlio de Mesquita Filho”, Araraquara. VYGOTSKY, Lev. Psicologi na revista. 